\title{
Association study of miR-149 rs2292832 and miR-608 rs4919510 and the risk of hepatocellular carcinoma in a large-scale population
}

\author{
RUI WANG $^{1,2^{*}}$, JUN ZHANG $^{1 *}$, YANYUN MA ${ }^{3}$, LINQI CHEN ${ }^{3}$, SHICHENG GUO $^{3}$, XIAOJIAO ZHANG $^{1,2}$, \\ YUNFANG MA ${ }^{1}$, LIJUN WU ${ }^{1}$, XIAOYU PEI ${ }^{1}$, SIRAN LIU $^{4}$, JIUCUN WANG $^{3}$, HEPING HU $^{5}$ and JIE LIU ${ }^{1,2}$ \\ ${ }^{1}$ Department of Digestive Diseases, Huashan Hospital, Fudan University, Shanghai 200040; \\ ${ }^{2}$ Department of Immunology of Shanghai Medical School and Institutes of Biomedical Sciences, \\ Fudan University, Shanghai 200032; ${ }^{3}$ Ministry of Education Key Laboratory of Contemporary Anthropology \\ and State Key Laboratory of Genetic Engineering, School of Life Sciences, Fudan University, Shanghai 200433, P.R. China; \\ ${ }^{4}$ Department of Biomedical Engineering, Northwestern University, Evanston, Illinois 60208, USA; \\ ${ }^{5}$ Eastern Hepatobiliary Surgery Hospital, The Second Military Medical University, Shanghai 200438, P.R. China
}

Received October 18, 2013; Accepted June 5, 2014

DOI: $10.3892 / \mathrm{mmr} .2014 .2536$

\begin{abstract}
Polymorphisms in pre-microRNAs (miRNAs) or mature miRNAs may influence miRNA processing or target binding, thus contributing to tumorigenesis and cancer development. The present study aimed to evaluate whether miR-149 rs2292832 (C>T) and miR-608 rs4919510 (G>C) are associated with the risk and clinical characteristics of hepatocellular carcinoma (HCC) in a large-scale population. miR-149 rs2292832 and miR-608 rs4919510 were genotyped in a total of 993 patients with HCC and 992 unrelated healthy subjects by Sequenom MassARRAY. The results showed that, compared with the reference CC genotype, the TC+TT genotype of miR-149 was more highly associated with HCC [CC vs. TC+TT: Odds ratio $(\mathrm{OR})=1.384,95 \%$ confidence interval $(\mathrm{CI})=1.013-1.892, \mathrm{P}=0.041]$, and was also associated with an increased risk of hepatitis B virus (HBV)-associated HCC (CC vs. TC+TT: $\mathrm{OR}=1.453,95 \% \mathrm{CI}=1.034-2.042, \mathrm{P}=0.031$ ). However, no significant association between miRNA-608 rs4919510 and the risk of $\mathrm{HCC} / \mathrm{HBV}$-associated HCC was found. In addition, these two SNPs were shown not to be

Correspondence to: Dr Jie Liu, Department of Digestive Diseases, Huashan Hospital, Fudan University, 12 Middle Wulumuqi Road, Shanghai 200040, P.R. China

E-mail: jieliu@fudan.edu.cn

Dr Heping Hu, Eastern Hepatobiliary Surgery Hospital, The Second Military Medical University, 225 Changhai Road, Shanghai 200438, P.R. China

E-mail: hp-hu@medmail.com.cn

*Contributed equally
\end{abstract}

Key words: microRNA, single nucleotide polymorphism, hepatocellular carcinoma, MassARRAY correlated with a range of clinical characteristics. The present study may provide an indicator for identification of the high risk of $\mathrm{HCC}$ in patients.

\section{Introduction}

Hepatocellular carcinoma (HCC) is one of the most common types of cancer worldwide, particularly in China (1). According to the latest Chinese cancer registration report, liver cancer accounts for the fourth highest morbidity and the second highest mortality rate of any type of cancer (2). In addition to hepatitis B (HBV) infection, other factors, including hepatitis $\mathrm{C}(\mathrm{HCV})$ infection, aflatoxin $\mathrm{B} 1$ exposure, genetic factors and excessive alcohol consumption also contribute to oncogenesis and development of HCC $(3,4)$. However, the genetic factors are poorly understood and require further exploration. Furthermore, due to the low diagnostic accuracy and poor prognosis of $\mathrm{HCC}$, investigation of highly efficient genetic biomarkers is essential.

MicroRNAs (miRNAs) are a class of small non-coding RNA molecules ( 22 nucleotides in length), which, as critical post-transcriptional regulators, modulate gene expression or function through binding to the 3'-untranslated region of targets. miRNAs have been predicted to regulate half of all protein-coding genes in mammals (5). Single nucleotide polymorphisms (SNPs) in pri-, pre- or mature miRNAs, particularly in the seed regions, may influence the expression or target site selection of miRNAs, and thus they may be involved in a wide range of biological processes and increase the risk of cancer $(6,7)$. Therefore, SNPs in miRNAs may be regarded as biomarkers for diagnosis and/or prognosis of cancers.

miR-149 rs2292832 (C>T) and miR-608 rs4919510 (G>C) have been predicted to be capable of influencing miRNA activities (8). miR-149 rs2292832 and mir-608 rs4919510 are involved in p53 signaling $(9,10)$, and studies have confirmed that they are linked to the susceptibility to certain types of cancer, including lung (11), gastric (12) and breast cancer (13), 
as well as head and neck squamous cell carcinoma (14) and colorectal cancer $(12,15)$. In particular, a previous study showed that miR-149 rs2292832 was associated with the risk of HCC in Korean individuals (16). No confirmation of this association in large and other ethnic populations has been reported, to the best of our knowledge. In addition, no studies have been performed to investigate the association between miR-608 rs4919510 and the risk of HCC to the best of our knowledge. Therefore, the present study aimed to determine whether these two polymorphisms were associated with HCC in a large-scale Chinese population.

\section{Materials and methods}

Patients. The final analysis in the present study consisted of 993 cases of HCC and 992 controls from an Eastern Chinese population sample collected from Huashan Hospital (Shanghai, China), Eastern Hepatobiliary Surgery Hospital (Shanghai, China) and CMC Institute of Health Sciences (Taizhou, China) as described previously (17). All patients were diagnosed by pathological or imaging evidence, while all controls were healthy without a family history of cancer or other serious diseases. Clinical characteristics collected included age, gender, family history, smoking status, alcohol use, serum $\alpha$ fetoprotein (AFP) levels, hepatitis B surface antigen (HBsAg) status, HBV-DNA titer, alanine transaminase (ALT) levels, aspartate aminotransferase (AST) levels, total bilirubin levels, tumor number/size and tumor grade. This study was approved by the Human Research Review Committee of Huashan Hospital, Fudan University (Shanghai, China). All patients or their families provided written informed consent.

DNA extraction. Genomic DNA was extracted from whole blood using the AxyPrep ${ }^{\mathrm{TM}}$ Blood Genomic DNA Miniprep kit (Axygen Biosciences, Union City, NJ, USA). Electrophoresis and concentration determination were performed for all DNA samples to ensure the accuracy of subsequent experiments. The concentration determination was conducted by NanoDrop 2000c Spectrophotometer (Thermo Fisher Scientific, Waltham, MA, USA). After NanoDrop software was opened and nucleic acid application was selected, $1 \mu 1 \mathrm{H}_{2} \mathrm{O}$ was pipetted on the pedestal for blank measurement, and then $1 \mu \mathrm{l}$ DNA sample was loaded onto the lower optical surface to measure its concentration. DNA samples with distinct strips in the electrophoresis gel and a concentration $>10 \mathrm{ng} / \mu \mathrm{l}$ were selected for further genotyping by Sequenom MassARRAY (Sequenom, San Diego, CA, USA).

Genotyping. The SNPs, miR-149 rs2292832 (C>T) and miR-608 rs4919510 (G>C), were genotyped using Sequenom MassARRAY technology. Polymerase chain reaction (PCR) primers were designed using MassARRAY Assay Design software version 3.1 (Sequenom), and synthesized by Shanghai Invitrogen Biotechnology Co., Ltd. (Shanghai, China). The primer sequences are listed in Table I. Sequencing was performed using the MassARRAY Analyzer Compact system (Sequenom) and analyzed by TYPER 4.0 (Sequenom). 
Table II. General characteristics in patients with HCC and controls, n (\%) or mean \pm standard deviation.

\begin{tabular}{|c|c|c|c|}
\hline Characteristic & Cases $(n=993)$ & Controls $(n=992)$ & P-value \\
\hline Age (years) & $54.63 \pm 11.26$ & $59.55 \pm 11.63$ & $<0.001^{\mathrm{a}}$ \\
\hline \multicolumn{4}{|l|}{ Gender } \\
\hline Male & $816(82.2)$ & $720(72.6)$ & \multirow[t]{2}{*}{$<0.001^{\circ}$} \\
\hline Female & $177(17.8)$ & $272(27.4)$ & \\
\hline \multicolumn{4}{|l|}{ Smoking status } \\
\hline Never & $663(67.7)$ & $523(52.7)$ & \multirow[t]{2}{*}{$<0.001^{\circ}$} \\
\hline Ever & $317(32.3)$ & $469(47.3)$ & \\
\hline \multicolumn{4}{|l|}{ Alcohol status } \\
\hline Never & $733(74.6)$ & $731(73.7)$ & 0.628 \\
\hline Ever & $249(25.4)$ & $261(26.3)$ & - \\
\hline \multicolumn{4}{|l|}{ HBsAg $(n=938)$} \\
\hline Negative & $179(18.9)$ & - & - \\
\hline Positive & $768(81.1)$ & - & - \\
\hline \multicolumn{4}{|l|}{ Tumor size $(\mathrm{n}=536)$} \\
\hline$<5 \mathrm{~cm}$ & $218(40.3)$ & - & - \\
\hline$\geq 5 \mathrm{~cm}$ & $323(59.7)$ & - & - \\
\hline \multicolumn{4}{|l|}{ Tumor number $(\mathrm{n}=535)$} \\
\hline Single & $477(88.3)$ & - & - \\
\hline Multiple & $63(11.7)$ & - & - \\
\hline \multicolumn{4}{|l|}{ Tumor grade $(\mathrm{n}=382)$} \\
\hline I-II & $85(22.0)$ & - & - \\
\hline III-IV & $301(78.0)$ & - & - \\
\hline \multicolumn{4}{|l|}{ Serum level of tumor markers } \\
\hline ALT (U/1, in 986 subjects) & $58.51 \pm 86.21$ & - & - \\
\hline AST (U/1, in 982 subjects) & $62.18 \pm 81.12$ & - & - \\
\hline \multicolumn{4}{|l|}{ AFP } \\
\hline$<20 \mu \mathrm{g} / 1$ & $361(37.2)$ & - & - \\
\hline$\geq 20 \mu \mathrm{g} / 1$ & $609(62.8)$ & - & - \\
\hline ( $\mu \mathrm{g} / 1$, in 402 subjects) & $127.32 \pm 289.25(0.7-1210)$ & - & - \\
\hline HBV-DNA (IU/ml, in 450 subjects) & $1.749 \times 10^{6} \pm 5.430 \times 10^{6}\left(1000-6.9 \times 10^{7}\right)$ & - & - \\
\hline
\end{tabular}

${ }^{\mathrm{a}} \mathrm{P}<0.05$ between the cases and controls. HCC, hepatocellular carcinoma; HBV, hepatitis B virus; HBsAg, hepatitis B surface antigen; ALT, alanine transaminase; AST, aspartate aminotransferase; AFP, $\alpha$ fetoprotein.

(Microsoft Corporation, Redmont, WA, USA) was applied to conduct the data analysis. Binary logistic regression was used to evaluate the correlation between the risk of HCC and the two SNPs adjusted to smoking, alcohol use and other confounding factors. Odds ratios (ORs) and 95\% confidence intervals (CI) were also calculated in order to estimate the relative risk. Pearson's $\chi^{2}$ test was performed to verify whether the sample obeyed the Hardy-Weinberg Equilibrium by comparing the observed genotype frequencies with the expected ones. The association between clinicopathological characteristics and genotypic/allelic frequencies in the patients with HCC was also conducted by Pearson's $\chi^{2}$ test. For the other quantitative variables which had heterogeneity of variance or non-normal distributions, analysis of variance or nonparametric tests were applied. All statistical tests were two-sided and probability levels $<0.05$ were used as a criterion of significance.

\section{Results}

General characteristics of the subjects. As Eastern China, including Jiangsu and Zhejiang provinces, is one of the main high-prevalence regions for HCC (2), a total of 993 patients with HCC and 992 healthy subjects were enrolled from the aforementioned provinces in the present study. The overview of the enlisted samples is presented in Table II. In terms of the distributions of age, gender and smoking status, significant differences between the cases and controls were identified: The control group had a higher age, higher female ratio and higher smoking ratio.

miRNA SNPs and the risk of HCC. Genotyping for rs2292832 and rs4919510 was successful in 1,928 and 1,985 subjects, respectively. The genotype distributions of 







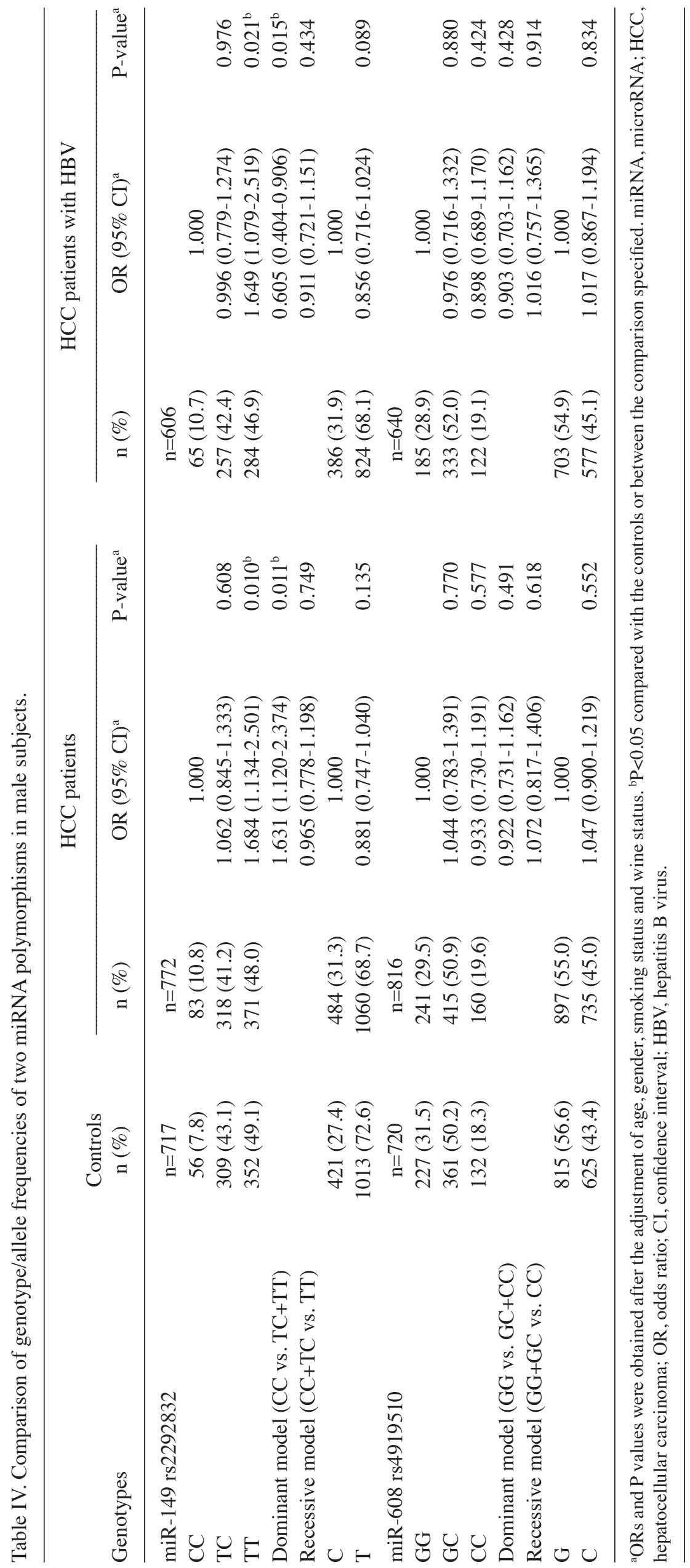




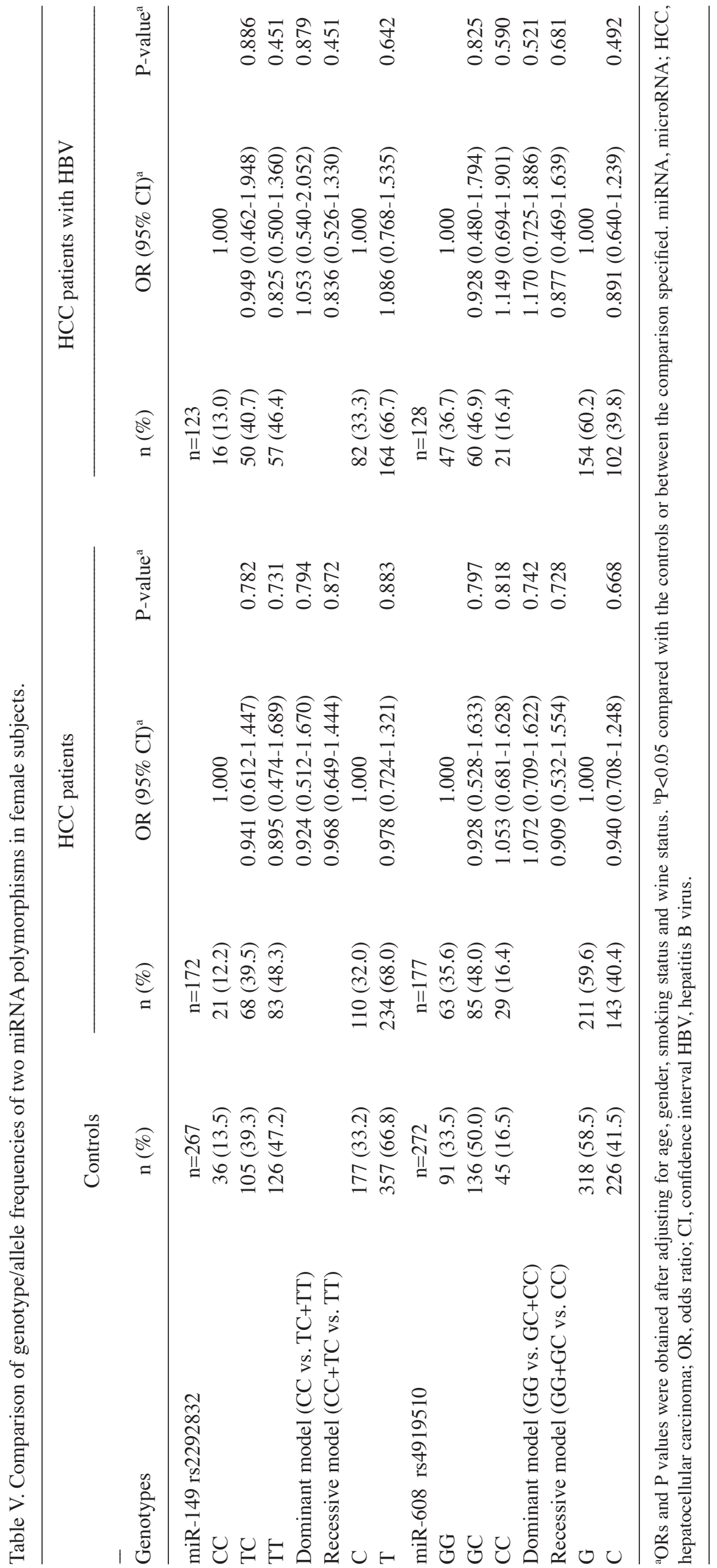


Table VI. Clinicopathological characteristics and genotype/allele frequencies of miR-149 and miR-608 polymorphisms in patients with $\mathrm{HCC}, \mathrm{n}(\%)$ or mean \pm standard deviation.

\begin{tabular}{|c|c|c|c|c|c|c|c|}
\hline \multirow{2}{*}{$\begin{array}{l}\text { Indexes } \\
\text { Tumor size }\end{array}$} & \multicolumn{3}{|c|}{ Genotype } & \multirow[t]{2}{*}{ P-value } & \multicolumn{2}{|c|}{ Allele } & \multirow[t]{2}{*}{ P-value } \\
\hline & & & & & & & \\
\hline miR-149 rs2292832 & $\mathrm{CC}$ & $\mathrm{TC}$ & TT & 0.720 & $\mathrm{C}$ & $\mathrm{T}$ & 0.430 \\
\hline$<5 \mathrm{~cm}$ & $23(11.0)$ & $88(41.9)$ & $99(47.1)$ & & $134(31.9)$ & $286(68.1)$ & \\
\hline$\geq 5 \mathrm{~cm}$ & $40(13.1)$ & $129(42.3)$ & $136(44.6)$ & & $209(34.3)$ & $401(65.7)$ & \\
\hline miR-608 rs4919510 & GG & $\mathrm{GC}$ & $\mathrm{CC}$ & 0.514 & G & $\mathrm{C}$ & 0.257 \\
\hline$<5 \mathrm{~cm}$ & $57(26.1)$ & $111(50.9)$ & $50(22.9)$ & & $225(51.6)$ & 211(48.4) & \\
\hline$\geq 5 \mathrm{~cm}$ & $98(30.3)$ & $160(49.5)$ & $65(20.1)$ & & $356(55.1)$ & $290(44.9)$ & \\
\hline \multicolumn{8}{|l|}{ Tumor focus number } \\
\hline miR-149 rs2292832 & $\mathrm{CC}$ & $\mathrm{TC}$ & TT & 0.650 & $\mathrm{C}$ & $\mathrm{T}$ & 0.344 \\
\hline Single & $57(12.6)$ & $193(42.5)$ & 204 (44.9) & & 307 (33.8) & $601(66.2)$ & \\
\hline Multiple & $6(9.8)$ & $24(39.3)$ & $31(50.8)$ & & $36(29.5)$ & $86(70.5)$ & \\
\hline miR-608 rs4919510 & GG & GC & $\mathrm{CC}$ & 0.430 & G & $\mathrm{C}$ & 0.205 \\
\hline Single & $140(29.4)$ & $239(50.1)$ & $98(20.5)$ & & $519(54.4)$ & $435(45.6)$ & \\
\hline Multiple & $15(23.8)$ & $31(49.2)$ & $17(27.0)$ & & $61(48.4)$ & $65(51.6)$ & \\
\hline \multicolumn{8}{|l|}{ Tumor grade } \\
\hline miR-149 rs2292832 & $\mathrm{CC}$ & $\mathrm{TC}$ & $\mathrm{TT}$ & 0.971 & $\mathrm{C}$ & $\mathrm{T}$ & 0.908 \\
\hline I-II & $11(13.6)$ & $34(42.0)$ & $36(44.4)$ & & $56(34.6)$ & $106(65.4)$ & \\
\hline III-IV & $40(13.8)$ & $117(40.5)$ & $132(45.7)$ & & $197(34.1)$ & $381(65.9)$ & \\
\hline miR-608 rs4919510 & GG & $\mathrm{GC}$ & $\mathrm{CC}$ & 0.818 & $\mathrm{G}$ & $\mathrm{C}$ & 0.538 \\
\hline I-II & $27(31.8)$ & $42(49.4)$ & $16(18.8)$ & & $96(56.5)$ & $74(43.5)$ & \\
\hline III-IV & $86(28.5)$ & $153(50.7)$ & $63(20.8)$ & & $325(53.8)$ & $279(46.2)$ & \\
\hline \multicolumn{8}{|l|}{ AFP } \\
\hline miR-149 rs2292832 & $\mathrm{CC}$ & $\mathrm{TC}$ & TT & 0.460 & $\mathrm{C}$ & $\mathrm{T}$ & 0.264 \\
\hline$<20 \mu \mathrm{g} / 1$ & $36(10.4)$ & 134 (38.6) & $177(51.0)$ & & $206(29.7)$ & $488(70.3)$ & \\
\hline$\geq 20 \mu \mathrm{g} / \mathrm{l}$ & $64(11.1)$ & $242(42.1)$ & $269(46.8)$ & & $370(32.2)$ & $780(67.8)$ & \\
\hline miR-608 rs4919510 & GG & GC & $\mathrm{CC}$ & 0.355 & G & $\mathrm{C}$ & 0.684 \\
\hline$<20 \mu \mathrm{g} / 1$ & $103(28.5)$ & $192(53.2)$ & $66(18.3)$ & & $398(55.1)$ & $324(44.9)$ & \\
\hline$\geq 20 \mu \mathrm{g} / 1$ & $194(31.9)$ & $295(48.4)$ & $120(19.7)$ & & $683(56.1)$ & $535(43.9)$ & \\
\hline \multicolumn{8}{|l|}{ Total bilirubin } \\
\hline miR-149 rs2292832 & $\mathrm{CC}$ & $\mathrm{TC}$ & $\mathrm{TT}$ & 0.831 & - & - & - \\
\hline & $19.49 \pm 36.99$ & $18.03 \pm 16.51$ & $18.64 \pm 28.17$ & & - & - & \\
\hline miR-608 rs4919510 & GG & GC & $\mathrm{CC}$ & 0.609 & - & - & - \\
\hline & $17.87 \pm 15.41$ & $18.69 \pm 27.83$ & $17.87 \pm 15.41$ & & - & - & \\
\hline \multicolumn{8}{|l|}{ Direct bilirubin } \\
\hline miR-149 rs2292832 & $\mathrm{CC}$ & $\mathrm{TC}$ & $\mathrm{TT}$ & 0.884 & - & - & - \\
\hline & $9.58 \pm 28.65$ & $8.36 \pm 12.65$ & $8.51 \pm 20.00$ & & - & - & \\
\hline miR-608 rs4919510 & GG & GC & $\mathrm{CC}$ & 0.564 & - & - & - \\
\hline & $10.01 \pm 29.18$ & $8.63 \pm 20.14$ & $7.95 \pm 10.91$ & & - & - & \\
\hline \multicolumn{8}{|l|}{ Indirect bilirubin } \\
\hline miR-149 rs2292832 & $\mathrm{CC}$ & $\mathrm{TC}$ & $\mathrm{TT}$ & 0.847 & - & - & - \\
\hline & $9.98 \pm 8.87$ & $9.71 \pm 5.18$ & $9.71 \pm 6.94$ & & - & - & \\
\hline miR-608 rs4919510 & GG & GC & $\mathrm{CC}$ & 0.416 & - & - & - \\
\hline & $10.14 \pm 8.79$ & $9.65 \pm 6.87$ & $10.00 \pm 5.58$ & & - & - & \\
\hline \multicolumn{8}{|l|}{$\operatorname{ALT}(\mathrm{U} / \mathrm{l})$} \\
\hline miR-149 rs2292832 & $\mathrm{CC}$ & $\mathrm{TC}$ & $\mathrm{TT}$ & 0.456 & - & - & - \\
\hline & $54.43 \pm 88.63$ & $60.95 \pm 88.86$ & $55.45 \pm 77.07$ & & - & - & \\
\hline
\end{tabular}


Table VI. Continued.

\begin{tabular}{|c|c|c|c|c|c|c|c|}
\hline Indexes & & Genotype & & $\mathrm{P}$-value & Allele & P-value & \\
\hline miR-608 rs4919510 & $\begin{array}{c}\mathrm{GG} \\
61.23 \pm 86.06\end{array}$ & $\begin{array}{c}\mathrm{GC} \\
56.76 \pm 85.23\end{array}$ & $\begin{array}{c}\mathrm{CC} \\
58.78 \pm 89.34\end{array}$ & 0.227 & $\begin{array}{l}- \\
-\end{array}$ & $\begin{array}{l}- \\
-\end{array}$ & - \\
\hline \multicolumn{8}{|l|}{$\operatorname{AST}(\mathrm{U} / 1)$} \\
\hline miR-149 rs2292832 & $\begin{array}{c}\mathrm{CC} \\
52.34 \pm 61.28\end{array}$ & $\begin{array}{c}\mathrm{TC} \\
66.4 \pm 91.04\end{array}$ & $\begin{array}{c}\mathrm{TT} \\
61.77 \pm 79.19\end{array}$ & 0.106 & - & $\begin{array}{l}- \\
-\end{array}$ & - \\
\hline miR-608 rs4919510 & $\begin{array}{c}\mathrm{GG} \\
64.20 \pm 88.57\end{array}$ & $\begin{array}{c}\mathrm{GC} \\
61.30 \pm 76.62\end{array}$ & $\begin{array}{c}\mathrm{CC} \\
61.27 \pm 80.55\end{array}$ & 0.888 & - & $\begin{array}{l}- \\
-\end{array}$ & - \\
\hline \multicolumn{8}{|l|}{ HBV-DNA (IU/ml) } \\
\hline miR-149 rs2292832 & $\begin{array}{c}\mathrm{CC} \\
8.72 \times 10^{5} \pm 1.59 \times 10^{6}\end{array}$ & $\begin{array}{c}\text { TC } \\
2.27 \times 10^{6} \pm 7.38 \times 10^{6}\end{array}$ & $\begin{array}{c}\mathrm{TT} \\
1.42 \times 10^{6} \pm 3.61 \times 10^{6}\end{array}$ & 0.526 & - & $\begin{array}{l}- \\
-\end{array}$ & - \\
\hline miR-608 rs4919510 & $\begin{array}{c}\text { GG } \\
2.92 \times 10^{6} \pm 8.33 \times 10^{6}\end{array}$ & $\begin{array}{c}\mathrm{GC} \\
1.23 \times 10^{6} \pm 3.24 \times 10^{6}\end{array}$ & $\begin{array}{c}\mathrm{CC} \\
1.10 \times 10^{6} \pm 2.76 \times 10^{6}\end{array}$ & 0.456 & $\begin{array}{l}- \\
-\end{array}$ & $\begin{array}{l}- \\
-\end{array}$ & - \\
\hline
\end{tabular}

miRNA, microRNA; HCC, hepatocellular carcinoma; HBsAg, hepatitis B surface antigen; HBV, hepatitis B virus; ALT, alanine transaminase; AST, aspartate aminotransferase; AFP, $\alpha$ fetoprotein.

the two SNPs in the case and control groups conformed to the Hardy-Weinberg Equilibrium. Table III shows that the frequency distribution of the miR-149 rs2292832 genotype was significantly different between the patients with HCC and the control group following adjustment of age, gender, smoking and alcohol consumption status. Compared with that of the wild type $\mathrm{CC}$, the TT genotype was associated with an increased risk of $\mathrm{HCC}(\mathrm{OR}=1.401,95 \%$ $\mathrm{CI}=1.007-1.950, \mathrm{P}=0.046)$; however, the genotype was not correlated with that of $\mathrm{HBV}$-associated $\mathrm{HCC}(\mathrm{OR}=1.419,95 \%$ $\mathrm{CI}=0.990-2.034, \mathrm{P}=0.057)$. According to the genetic model analysis, in comparison with that of the wild-type $\mathrm{CC}$, the TC+TT genotype was correlated with a higher risk of HCC ( $\mathrm{OR}=1.384,95 \% \mathrm{CI}=1.013-1.892, \mathrm{P}=0.041)$, as well as that of HBV-associated HCC $(\mathrm{OR}=1.453,95 \% \mathrm{CI}=1.034-2.042$, $\mathrm{P}=0.031$ ), indicating its dominant manner. Furthermore, further gender analysis (Table IV) implicated the association in males. Male subjects with the miR-149 TT genotype were associated with an increased risk of $\mathrm{HCC} / \mathrm{HBV}$-associated HCC as compared with the CC genotypes ( $\mathrm{HCC}, \mathrm{OR}=1.684$, 95\% $\mathrm{CI}=1.134-2.501, \mathrm{P}=0.010 ; \mathrm{HBV}$-associated $\mathrm{HCC}$, $\mathrm{OR}=1.649,95 \% \mathrm{CI}=1.079-2.519, \mathrm{P}=0.021$, respectively). However, in females, this association was not identified (Table V).

As for miR-608 rs4919510, the frequency distributions of genotypes or alleles did not display statistically significant differences between the cases and the controls of $\mathrm{HCC} / \mathrm{HBV}$-associated HCC $(\mathrm{P}>0.05)$.

miRNA-499 and miR-608 polymorphisms and clinicopathological characteristics. Whether clinicopathological characteristics have an association with the distribution of genotypes/alleles was further analyzed. As shown in Table VI, no significant differences were discovered, implying that the two SNPs were uncorrelated with clinicopathological characteristics.

\section{Discussion}

Aberrant miRNA expression or function may alter a wide variety of physiological processes. SNPs in miRNA genes are able to influence the biogenesis and functions of their host miRNAs, and thus they participate in the susceptibility of developing complicated diseases (4). The present study identified for the first time, to the best of our knowledge, that rs2292832 in miR-149 had significant correlation with genetic predisposition to HCC and HBV-associated HCC in a large-scale Chinese population, while no correlation existed between miR-608 rs4919510 and the risk of HCC/HBV-associated HCC. Furthermore, the two SNPs lacked an association with the clinical characteristics recorded.

miR-149 functions as a tumor suppressor by promoting apoptosis through repression of Akt1 and E2F1 (as observed in HeLa cells and the Be2C neuroblastoma cell line) (18), by inhibiting epithelial-to-mesenchymal transition by targeting of Forkhead box M1 (in lung cancer cells) (19), or by targeting of the zinc finger and BTB domain containing 2 oncogene (in gastric cancer) (20). miR-149 is also a tumor oncogene regulator which is involved in the increased expression levels of myeloid cell leukemia sequence 1 (in human melanoma) (10). However, whether miR-149 is involved in the carcinogenesis and development of HCC remains unknown. To the best of our knowledge, there is only one study that has suggested an association between the miR-149 rs2292832 polymorphism and $\mathrm{HCC} / \mathrm{HBV}-\mathrm{HCC}$, and the study used a small Korean sample (cases/controls $=159: 201)$ (16). With a larger Chinese sample, the present study disclosed that individuals with the TC+TT genotype had a higher risk of $\mathrm{HCC} / \mathrm{HBV}$-associated $\mathrm{HCC}$, compared with that of individuals with the $\mathrm{CC}$ genotypes. As the $\mathrm{T}$ variant in pre-miRNA-149 may prohibit the expression of mature miR-149 (14), the findings of the present study indicated that miR-149, as a tumor suppressor, was downregulated 
in subjects with the TC+TT genotypes and thus resulted in an increased risk of $\mathrm{HCC}$.

miR-608 is mapped in the 10q24 locus, at which a loss of heterozygosity exists in certain types of tumor, including colorectal, prostate, pancreatic and brain (21-23). A variant, rs4919510, is embodied in the mature sequence of miR-608, within an intron of sema domain, immunoglobulin domain (Ig), transmembrane domain (TM) and short cytoplasmic domain (semaphorin) 4G (24). A study predicted that common/variant miR-608 binds to its targets, including acyl-CoA dehydrogenase, $\mathrm{CD} 4$, growth hormone receptor, retinoid $\mathrm{X}$ receptor $\beta$ and tumor protein p53 (involved in hepatocarcinogenesis), with different levels of energy and result in different biological activities (25). Furthermore, miR-605 may create a positive feedback loop by assisting the rapid accumulation of p53 in response to stress through interruption of the p53:Mdm2 interaction (9). Therefore, it was assumed that the variant may influence the risk of HCC, serving as a predictive biomarker. However, the results of the present study showed that miR-608 rs4919510 was not correlated with the risk of $\mathrm{HCC} / \mathrm{HBV}$-associated $\mathrm{HCC}$, or clinical features, at least in the population studied.

In conclusion, to the best of our knowledge, the results of the present study demonstrated for the first time that the miR-149 rs2292832 polymorphism may influence genetic predisposition to $\mathrm{HCC} / \mathrm{HBV}$-associated $\mathrm{HCC}$ in the Chinese population, particularly in males, while the miR-608 rs4919510 polymorphism lacked such association in the studied population. The present study lays a foundation for further studies regarding the function of miR-149 in HCC by suggesting that miR-149 may be useful as an indicator for early detection of HCC risk.

\section{Acknowledgements}

This study was supported by grants from the National Natural Science Foundation of China (nos. 81125001 and 91129702), the Ministry of Science and Technology of the People's Republic of China (no. 2010CB732405) and the Shanghai Municipal Science and Technology Commission (nos. 12JC1402000 and 12410705300).

\section{References}

1. Jemal A, Bray F, Center MM, Ferlay J, Ward E and Forman D: Global cancer statistics. CA Cancer J Clin 61: 69-90, 2011.

2. Hao J and Chen WQ: The 10 most common cancers in all registration areas. In: Chinese Cancer Registry Annual Report (2012) Military Medical Science Press, Beijing, China, pp27-31, 2012.

3. El-Serag HB and Rudolph KL: Hepatocellular carcinoma: epidemiology and molecular carcinogenesis. Gastroenterology 132 2557-2576, 2007.

4. Gramantieri L, Fornari F, Callegari E, et al: MicroRNA involvement in hepatocellular carcinoma. J Cell Mol Med 12: 2189-2204, 2008.

5. Krol J, Loedige I and Filipowicz W: The widespread regulation of microRNA biogenesis, function and decay. Nat Rev Genet 11: $597-610,2010$
6. Slaby O, Bienertova-Vasku J, Svoboda M and Vyzula R: Genetic polymorphisms and microRNAs: new direction in molecular epidemiology of solid cancer. J Cell Mol Med 16: 8-21, 2012.

7. Mishra PJ and Bertino JR: MicroRNA polymorphisms: the future of pharmacogenomics, molecular epidemiology and individualized medicine. Pharmacogenomics 10: 399-416, 2009.

8. Duan S, Mi S, Zhang W and Dolan ME: Comprehensive analysis of the impact of SNPs and CNVs on human microRNAs and their regulatory genes. RNA Biology 6: 412-425, 2009.

9. Xiao J, Lin H, Luo X, Luo X and Wang Z: miR-605 joins p53 network to form a p53:miR-605:Mdm2 positive feedback loop in response to stress. EMBO J 30: 524-532, 2011.

10. Jin L, Hu WL, Jiang CC, Wang JX, et al: MicroRNA-149*, a p53-responsive microRNA, functions as an oncogenic regulator in human melanoma. Proc Natl Acad Sci USA 108: 15840-15845, 2011.

11. Hong MJ Choi YY, Jang JA, Jung HJ, et al: Association between genetic variants in pre-microRNAs and survival of early-stage NSCLC. J Thorac Oncol 8: 703-710, 2013.

12. Zhang MW, Jin MJ, Yu YX, et al: Associations of lifestyle-related factors, hsa-miR-149 and hsa-miR-605 gene polymorphisms with gastrointestinal cancer risk. Mol Carcinog 51 (Suppl 1): E21-E31, 2012.

13. Huang AJ, Yu KD, Li J, Fan L and Shao ZM: Polymorphism rs4919510:C $>\mathrm{G}$ in mature sequence of human microRNA-608 contributes to the risk of HER2-positive breast cancer but not other subtypes. PLoS One 7: e35252, 2012.

14. Tu HF, Liu CJ, Chang CL, Wang PW, et al: The association between genetic polymorphism and the processing efficiency of miR-149 affects the prognosis of patients with head and neck squamous cell carcinoma. PLoS One 7: e51606, 2012.

15. Xing J, Wan S, Zhou F, et al: Genetic polymorphisms in pre-microRNA genes as prognostic markers of colorectal cancer. Cancer Epidemiol Biomarkers Prev 21: 217-227, 2012.

16. Kim WH, Min KT, Jeon YJ, et al: Association study of microRNA polymorphisms with hepatocellular carcinoma in Korean population. Gene 504: 92-97, 2012.

17. Zhang J, Wang R, Ma YY, Chen LQ, Jin BH, et al: Association between the single nucleotide polymorphisms in miRNA196a-2 and miRNA146a and the susceptibility to hepatocellular carcinoma in a Chinese population. Asian Pac J Cancer Prev 14: 6427-6431, 2013.

18. Lin RJ, Lin YC and Yu AL: miR-149* induces apoptosis by inhibiting Akt1 and E2F1 in human cancer cells. Mol Carcinog 49: 719-727, 2010.

19. Ke Y,Zhao W, Xiong J and Cao R: miR-149 inhibits non-small-cell lung cancer cells EMT by targeting FOXM1. Biochem Res Int 2013: 506731, 2013.

20. Wang Y, Zheng X, Zhang Z, et al: MicroRNA-149 inhibits proliferation and cell cycle progression through the targeting of ZBTB2 in human gastric cancer. PLoS One 7: e41693, 2012.

21. Bashyam MD, Bair R, Kim YH, et al: Array-based comparative genomic hybridization identifies localized DNA amplifications and homozygous deletions in pancreatic cancer. Neoplasia 7 : 556-562, 2005

22. Daido S, Takao S, Tamiya T, Ono Y, et al: Loss of heterozygosity on chromosome 10q associated with malignancy and prognosis in astrocytic tumors, and discovery of novel loss regions. Oncol Rep 12: 789-795, 2004.

23. Kim JH, Dhanasekaran SM, Mehra R, et al: Integrative analysis of genomic aberrations associated with prostate cancer progression. Cancer Res 67: 8229-8239, 2007.

24. Ryan BM, McClary AC, Valeri N, Robinson D, et al: rs4919510 in hsa-mir-608 is associated with outcome but not risk of colorectal cancer. PLoS One 7: e36306, 2012.

25. Landi D, Gemignani F, Barale R and Landi S: A catalog of polymorphisms falling in microRNA-binding regions of cancer genes. DNA Cell Biol 27: 35-43, 2008. 